\title{
Tectonics and sedimentation during convergence of the ALCAPA and Tisza-Dacia continental blocks: The Pienide nappe emplacement and its foredeep (N. Romania)
}

\author{
M. Tischler ${ }^{1,4)}$, L. Matenco ${ }^{2)}$, S. Filipescu ${ }^{3)}$, H.R. Gröger ${ }^{1,4)}$, A. Wetzel ${ }^{1)}$ \& B. FüGensChuh ${ }^{5)}$
}

1) Geologisch-Paläontologisches Institut, Universität Basel, Bernoullistr. 35, 4058 Basel, Switzerland (m.tischler@ unibas.ch)

2) Netherlands Centre for Integrated Solid Earth Sciences, Vrije Universiteit, Faculty of Earth and Life Sciences, De Boelelaan 1085, 1081 HV Amsterdam, The Netherlands (liviu.matenco@falw.vu.nl)

3) Department of Geology, Babes-Bolyai University, Str. Kogalniceanu 1, 400084 Cluj-Napoca, Romania

4) Present address: Statoil ASA, Statoil Head office, Forusbeen 50, 4035 Stavanger, Norway

5) Geology and Paleontology, Innsbruck University, Innrain 52f, A-6020 Innsbruck, Austria

\section{Supplementary publication: Facies analysis}

Detailed stratigraphic logs have been compiled from outcropanalysis. To subdivide the lithostratigraphic logs on the basis of depositional trends, the hierarchical system of Mutti \& Normark (1987) has been used. First order features are at the scale of basin fills (turbidite complex), while second order features (turbidite system, $\sim 400 \mathrm{~m}$ thickness) include depositional sequences, commonly bounded by highstand mud facies. Third order features (turbidite stage, $\sim 250 \mathrm{~m}$ thickness) are facies associations reflecting different development phases of the system. Fourth order features comprise bed packages (turbidite sub-stage, $\sim 15 \mathrm{~m}$ ) and characterize sub-stages of system development. The smallest, fifth division, is defined by individual lithofacies.

The lithofacies classification is based on Pickering et al. (1989, 1995). This classification scheme aids in the interpretation of the depositional processes, without implying genetic relations between lithofacies. The lithofacies were then grouped into lithofacies associations, which can be interpreted in terms of depositional environments. The various lithofacies are outlined in Table SP1 and illustrated in Figures SP1 and SP2.

Only continuous sections, individually long enough for a meaningful discussion of the development of the depositional setting, have been included. The logs described below are situated within the autochthonous domains 1, 3 and 4 (Fig. 3 of the main publication), reaching from Early Oligocene to Early Miocene times. 


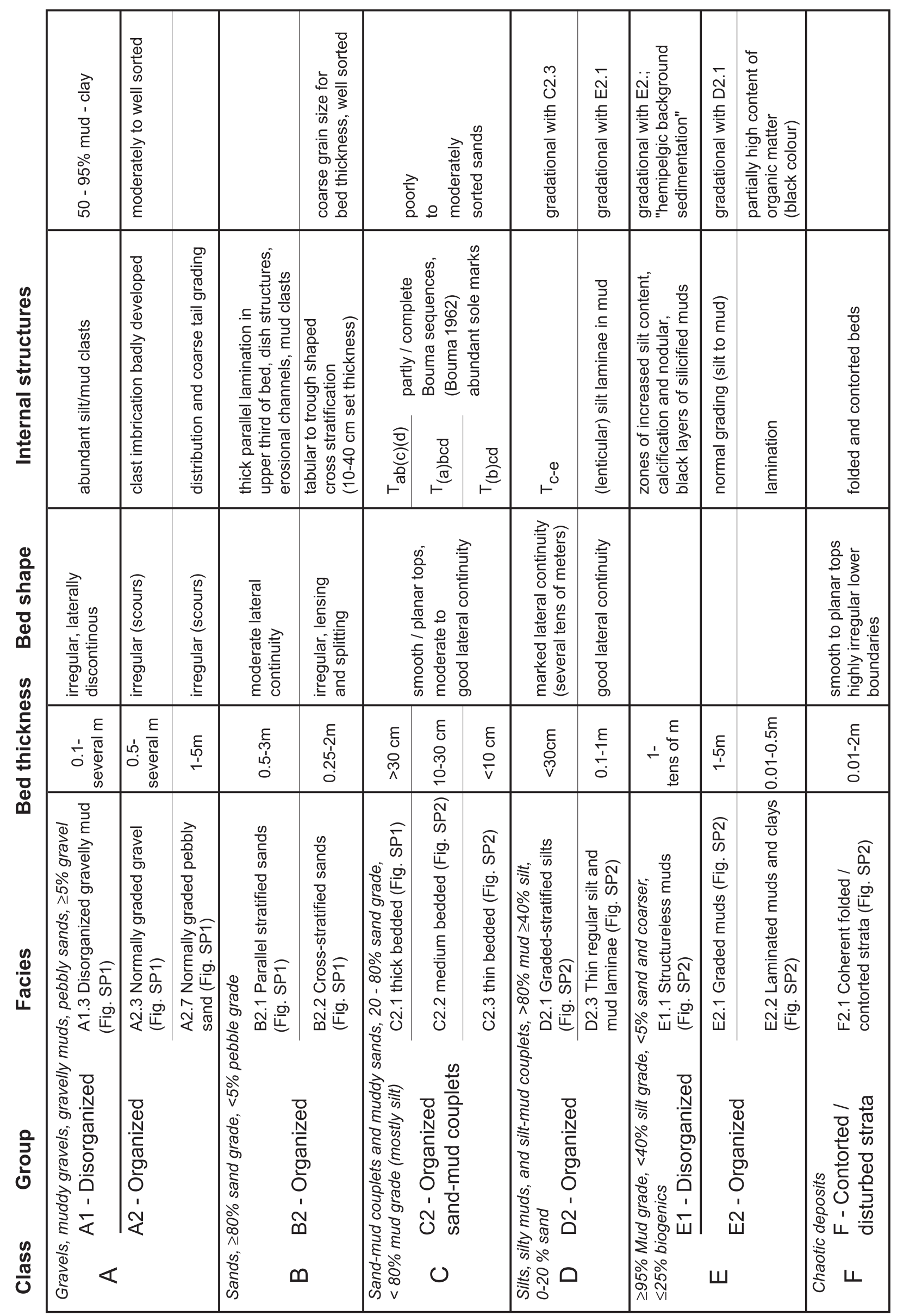

Table SP1: Overview on the lithofacies and their most important features (based on Pickering et al. 1989). 

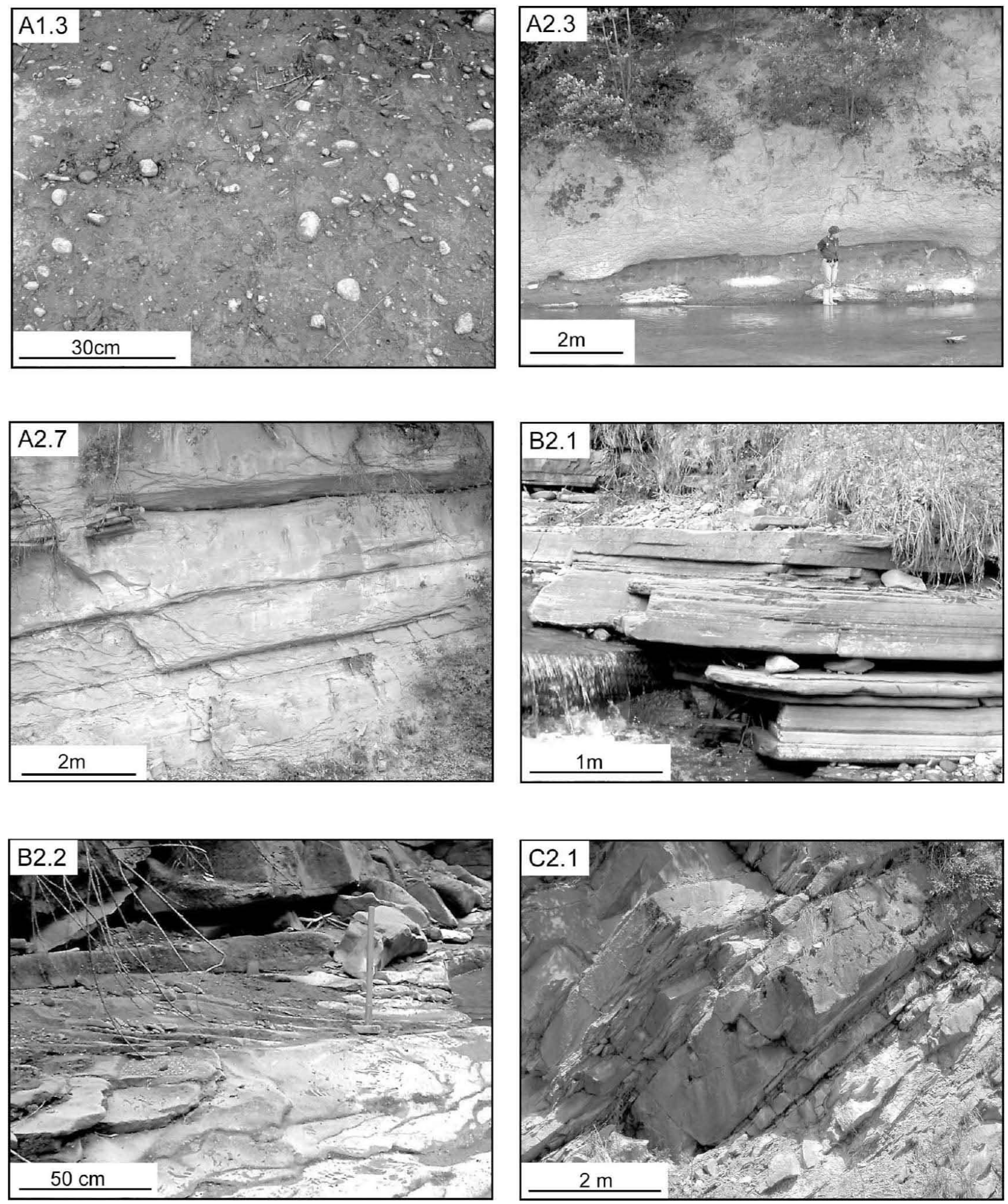

Fig. SP1: Field examples for facies classes used. The code in the upper left corner of the pictures correlates to the facies codes (based on Pickering et al. 1989, 1995, see Table SP1). 

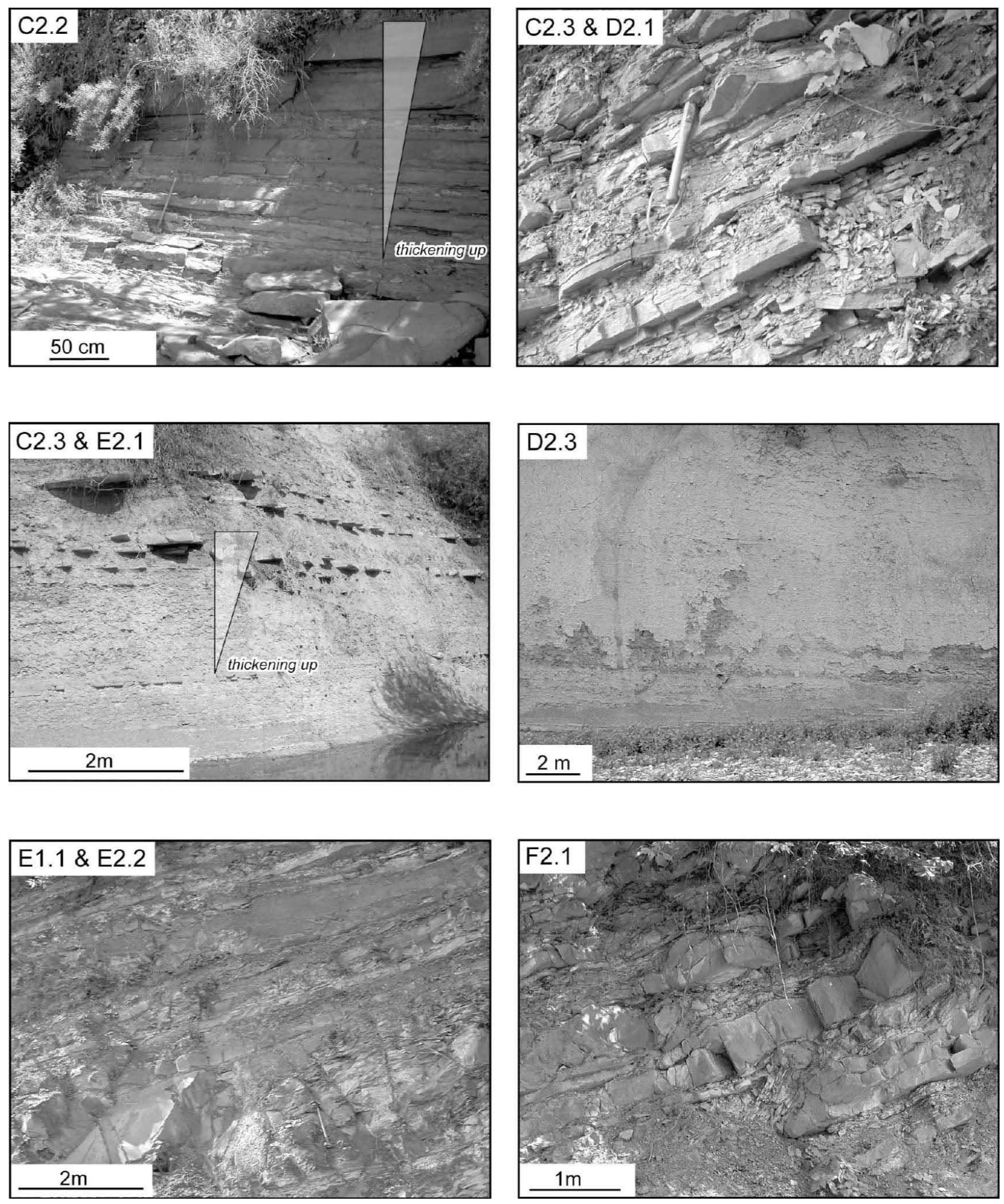

Fig. SP2: Field examples for facies classes used. The code in the upper left corner of the pictures correlates to the facies codes (based on Pickering et al. 1989, 1995, see Table SP1). 


\section{Facies associations of the lithostratigraphic logs}

\section{$\log 1$}

Log 1a (Fig. SP3) covers approximately 300m of a Lower Oligocene mud-dominated unit (Valea Carelor Fm.). Structureless muds (E1.1, 80\%) dominate, in which graded muds (E2.1, 15\%) and laminated muds $(\sim 5 \%)$ are embedded. An overall (3rd order) coarsening-up trend is evident from an increase in grain size of intercalated turbidites (graded muds, E2.1, towards graded-stratified silts, D2.1) as well as by an increasing amount of sandy turbidites. Depositional coarsening-up trends (4thorder) become more clearly defined towards the top.

Log $1 \mathrm{~b}$ shows a well-developed 4th-order coarsening-up trend composed of thin-bedded sand-mud couplets (C2.3) and graded-stratified silts (D2.1), confirming the general 3rd- order coarsening-up trend.

\section{Depositional setting:}

The occurrence of biogenic oozes and the relative abundance of fine-grained terrigenous material (graded muds, graded-stratified silts) implies a "distal basin" setting (Mutti \& Ricci Lucci 1972). The overall, 3rd order coarsening-up organized into 4th order coarsening-up trends are suggestive for a progradation towards a distal lobe environment (Mutti \& Normark 1987).

Fig. SP3: Lithostratigraphic logs $1 \mathrm{a}$ and $1 \mathrm{~b}$, covering approximately the topmost $70 \%$ of the Valea Carelor Fm. A general coarsening-up trend suggests a progradation from basin plain setting towards a distal lobe setting. 


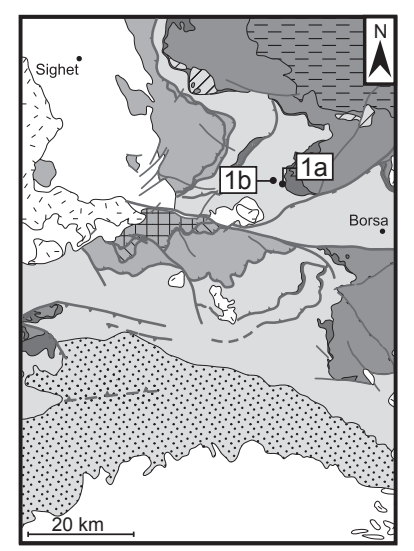

\section{Domain 1: northern autochthonous}
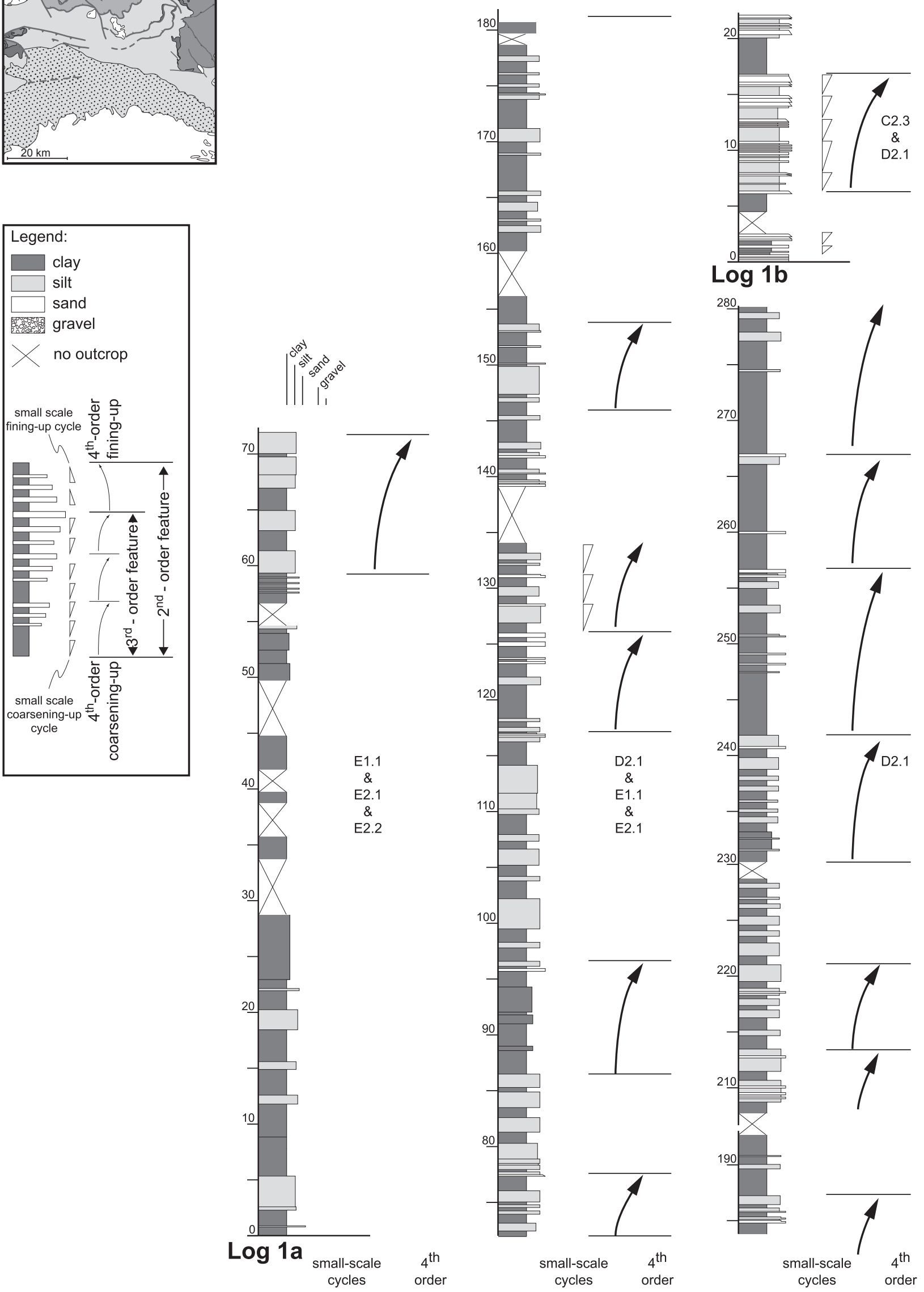


\section{$\log 2$}

Log 2 (Fig. SP4) covers around 500m of the Lower Oligocene sand-dominated deposits (Birțu Sandstone Fm.). In the lower 170m a 3rd order coarsening-up trend can be observed. Thin-bedded sand-mud couplets (C2.3), and graded muds (E2.1) grade into thick-bedded sand-mud couplets (C2.1). This overall coarsening-up trend is composed of four 4th-order coarsening-up trends. The lower third of a 4th-order bed package is dominated by small-scale ( 2 to $5 \mathrm{~m}$ ) thickening-up cycles (compensation cycles senso Mutti \& Normark 1987), while the upper part consists of small-scale (2 to 5m) fining-up cycles. Two 1 to $2 \mathrm{~m}$ thick layers of coherent folded and contorted strata occur between meter 130 and 140 .

The interval between $170 \mathrm{~m}$ and $290 \mathrm{~m}$ is dominated by sand-mud couplets (C) embedded in graded silts (D2.1), lacking clear depositional trends. An abrupt change occurs at meter 250, where normally graded pebbly sands (A2.7) are intercalated into thin-bedded sand-mud couplets.

The interval between $290 \mathrm{~m}$ and $340 \mathrm{~m}$ is dominated by very thick- to thick-bedded sand-mud couplets (C2.1) organized in two 4th-order thinning-up sequences. The topmost $130 \mathrm{~m}$ show an overall 3rdorder fining-up trend organized in 4th-order coarsening-up trends. Very thick/thick bedded sand-mud couplets (C2.1) grade into thin-bedded sand-mud couplets (C2.3) and graded-stratified silts (D2.1) intercalated into structureless muds (E1.1).

\section{Depositional setting:}

The clear coarsening-up of the lower $170 \mathrm{~m}$, arranged in well-developed 4th-order thickeningup trends (Fig. SP4), is interpreted to reflect fan progradation. This interval is ascribed to nonchannelized deposits of the distal to intermediate lobe setting. Slumped intervals at the top of this interval emphasize the development towards proximal settings.

Rather weakly developed depositional trends and channelized deposits (abrupt vertical facies changes) between 170 and $290 \mathrm{~m}$ are interpreted to reflect the transition from sheet-like lobe to channelized deposits. The thinning-up sequences of the interval between 290 and 340m are suggestive of channelized deposits at a channel-lobe transition. The gradual fining-up trend observed within the upper part, accompanied by clear 4th-order thickening up cycles, are explained by a retreat of the system.

Fig. SP4: Log 2, for legend see Fig. SP3. This log covers the complete Birțu Sandstone Fm., reaching into the mud-dominated Valea Morii Fm. This logs shows a well-documented example for a progradation from distal lobe settings to a channel-lobe transitional setting, followed by a retrogradation. 


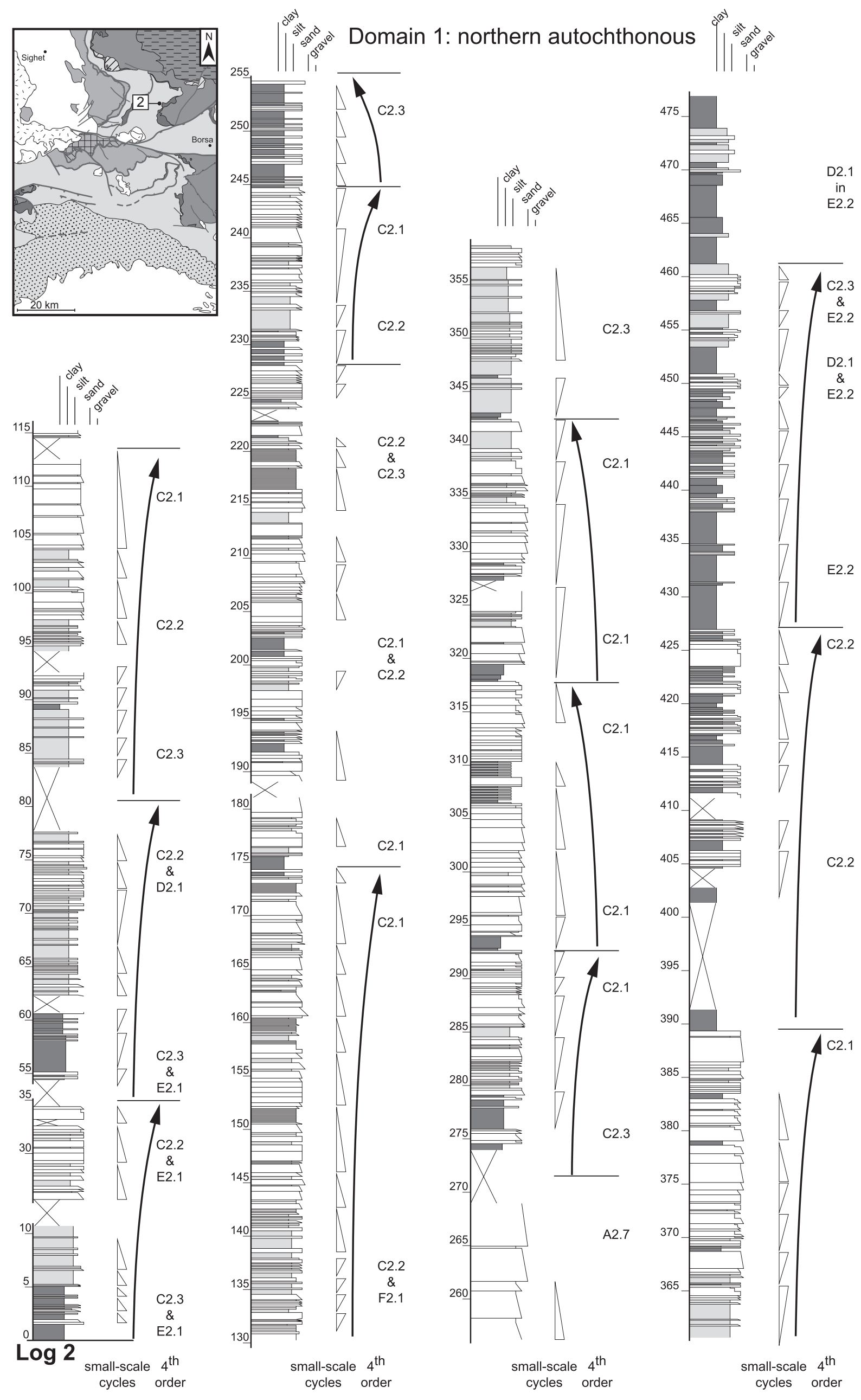




\section{$\log 3$}

Location 3 (Fig. SP5) is situated at the top of the Upper Oligocene to Lower Miocene mud-dominated unit of Domain 3 (Fig. 3 of the main publication). Organized sand-mud couplets (C2) are embedded in graded-stratified silts (D2.1) and laminated silts and muds (D2.2). The fine-grained parts of the succession feature intercalations of laminated muds and clays (E2.2). A general (3rd-order) coarseningup trend is reflected by grading from thin- to thick-bedded organized sand-mud couplets as well as an increase in silt content ( $\sim 30 \%$ to $\sim 60 \%)$ of the muddy facies. The overall trend is composed of five 4th-order coarsening-up cycles of $10-20 \mathrm{~m}$ thickness, comprising small-scale $(\sim 2.50 \mathrm{~m}$ thick$)$, predominantly coarsening-up cycles.

\section{Depositional setting:}

The general coarsening-up trend composed of well-defined 4th-order coarsening-up intervals as well as the lithofacies (D2.1 to C2.1) is suggestive of a relatively distal, prograding environment. These facies associations are ascribed to a distal basin to distal lobe setting (Mutti \& Ricci Lucci 1972).

\section{$\log 4$}

This log (Fig. SP5) covers approximately the lower two thirds of the Lower Miocene sand-dominated unit of Domain 3 (Fig. 3 of the main publication). It is composed of a 3rd-order coarsening-up sequence, followed by a 3rd-order fining-up interval, which in turn is overlain by deposits characterized by facies F2.1.

The basal (0 to $150 \mathrm{~m}) 3$ rd-order coarsening-up trend consists of three 4th-order coarsening-up cycles, each approximately 50m thick. The basal 4th-order coarsening-up sequence grades from medium bedded sand-mud couplets (C2.2), intercalated with thin regular silt and mud laminae (D2.2), into normally graded pebbly sand (A2.7; pebble sizes $\sim 1-2 \mathrm{~cm}$ ). The two 4th-order coarsening-up cycles further up-section grade from parallel-stratified sands (B2.1) to normally graded pebbly sand (A2.7), intercalations of cross-stratified sands (B2.2) are abundant. All of the basal coarsening-up cycles display small-scale (2 to $10 \mathrm{~m}$ ) fining-upward trends.

The fining- and thinning-up trend at the top of the section is dominated by parallel-stratified sands (B2.1), with intercalations of cross-stratified sands (B2.2). Within this 70m thick 4th-order cycle, small-scale thickening-up sequences are dominant. At the top, a $5 \mathrm{~m}$ thick disorganized gravely mud (A1.3, mean $8 \mathrm{~cm}$, max pebble size $20 \mathrm{~cm}$ ) is embedded into parallel-stratified sands (B2.1).

\section{Depositional setting:}

The coarsening-up trend documented in the lower part is interpreted to reflect a progradation of the system. Since the 4th-order thickening-up cycles within the basal part are characteristic for nonchannelized deposits, the depositional setting is interpreted as intermediate to proximal lobe. The upper part, characterized by a thinning-up trend is ascribed to a mid-fan setting, where channelized deposits dominate. The inferred progradation is supported by the occurrence of slump deposits (A1.3) in the topmost part.

Fig. SP5: Sedimentary logs 3 and 4. For legend see Fig. SP3. Log 3 is situated at the top of the Vima Fm. ( $\sim 10 \%$ total thickness of Fm.), showing a prograding distal lobe setting before the onset of sand-dominated sedimentation of the Minget Sandstone Fm. Log 4 covers the basal $\sim 70 \%$ of the Minget Sandstone Fm. A progradation from intermediate lobe to channel-lobe transitional settings is documented. 


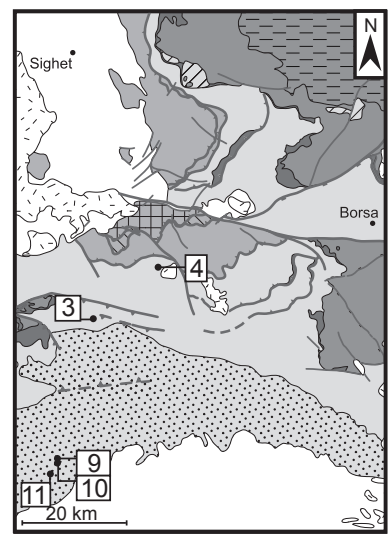

Domain 3: central autochthonous
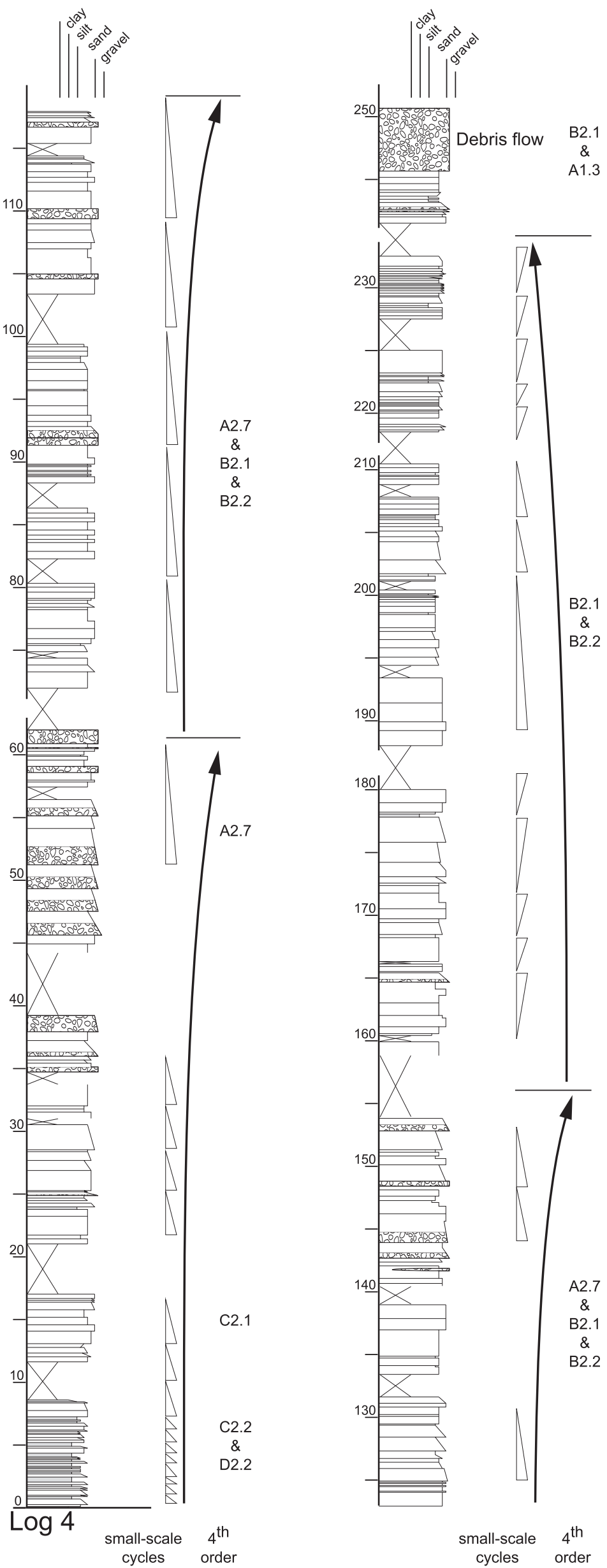


\section{Logs 5 and 6}

These logs (Fig. SP6) are situated at the base of the coarse-grained siliciclastics of Domain 4 (Fig. 3 of the main publication) and show a general (3rd-order) fining-up trend, normally graded gravel (A2.3) and normally graded pebbly sand (A2.7) grading into thick- to medium-bedded sand-mud couplets (C2.1/C2.2). The normally graded pebbly sands show thick parallel lamination and occasional cross bedding. The overall (3rd-order) fining-up trend is composed out of three 4th-order cycles.

\section{Depositional setting:}

The lithofacies and depositional sequences suggest channelized deposits, probably within a channellobe transitional setting (Mutti \& Normark 1987). The general fining-up trend might be interpreted as a channel fill.

\section{$\log 7$}

At the locality of $\log 7$, close to the base of the coarse-grained siliciclastics of Domain 4 (Fig. SP6), sand-mud couplets (C2) are intercalated with thin regular silt and mud laminae (D2.3). Although no general (3rd-order) depositional trend is evident, 4th-order trends are well developed. The log is dominated by six $\sim 15$ thick 4th-order coarsening-up cycles, each grading from medium-bedded (C2.2) to thick-bedded (C2.1) sand-mud couplets. At the top a thinning-up cycle is documented, thick bedded (C2.1) grading to medium-bedded (C2.2) sand-mud couplets.

\section{Depositional setting:}

The predominantly $\mathrm{C}$ and $\mathrm{D}$ facies class deposits, together with well developed 4th-order coarseningup cycles are interpreted as intermediate lobe deposits.

\section{$\log 8$}

Log 8 is starting approximately $200 \mathrm{~m}$ below the erosive base of the Dej Tuff Fm. It is build up by facies class A deposits (Fig. SP6), normally graded gravels (A2.3) and pebbly sands (A2.7) dominate. At the top of the log two debris flows (A1.3) occur. The facies class A deposits form a 3rd-order thinning-up trend. The clast-supported conglomerates show an overall decrease in clast size from 15 to $5 \mathrm{~cm}$ maximum diameter.

\section{Depositional setting:}

The lithofacies and the overall thinning-up trend suggest proximal channelized deposits. The depositional setting is interpreted to have been a channel.

Fig. SP6: Sedimentary logs 5 to 11. All of these logs are situated in the Hida Fm. Logs 5 to 7 stem from the basal part, $\operatorname{logs} 8$ to 11 cover the top $200 \mathrm{~m}$ of the Hida Formation. The progradational pulses are separated by mud-dominated intervals, showing an increasing silt content. Logs 9 and 10 are homogenously composed of facies D2.2, and only their location is indicated. 


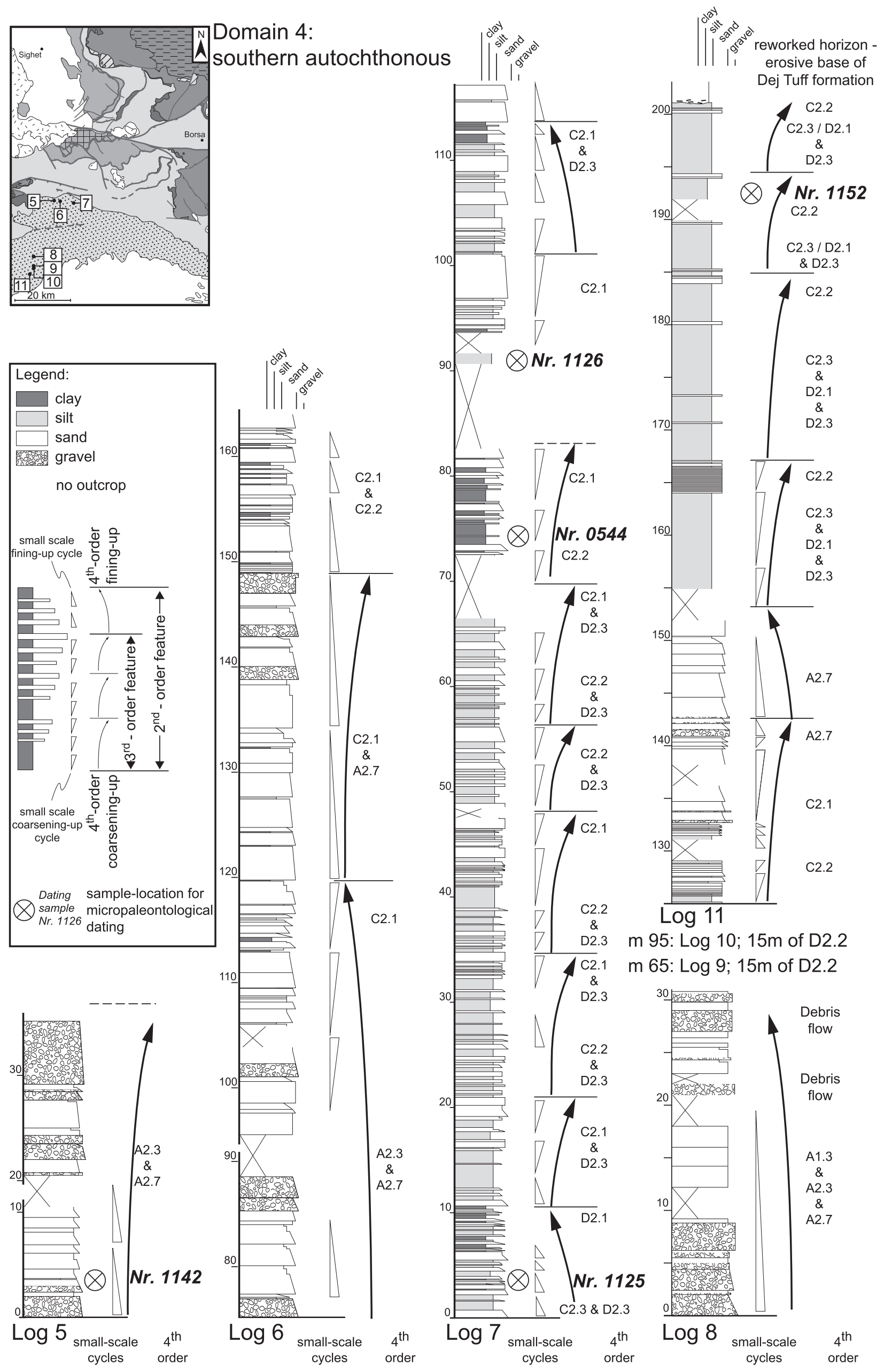




\section{Logs 9+10}

In the upper part of the coarse-grained siliciclastics of Domain 4 (9:150m below top; 10: 100m below top, Fig. SP6) homogeneous mud-dominated sediments are documented. Logs 9 and 10 feature thin regular silt and mud laminae (D2.3) with few intercalations of graded-stratified silts (D2.1). The mud to silt ratio decreases from 1:1 in $\log 9$ to $1: 3$ in $\log 10$.

\section{Depositional setting:}

The lithofacies of these logs suggests a distal, silt-rich setting, sharing the similarities of a distal basin setting (e.g. Mutti \& Ricchi Lucci 1972).

\section{$\log 11$}

Log 11 covers the topmost 70m of the coarse-grained siliciclastics of Domain 4. The top is formed by a reworking horizon, which marks the transgressive surface at the base of the Dej Tuff Fm. (Fig. SP6).

The base of this log shows a rapid 4th-order coarsening-up development from medium- (C2.2) over thick- (C2.1) bedded sand-mud couplets towards normally graded pebbly sands (A2.7). This trend is followed by a 4th-order thinning-up trend within normally graded pebbly sands. The top of the $\log$ consists of graded-stratified silts (D2.1), thin regular silt and mud laminae (D2.3) in which sand-mud couplets are embedded. These intercalated sand-mud couplets define four small-sale coarsening-up trends $(\sim 15 \mathrm{~m}$ thickness), each grading from thin $(\mathrm{C} 2.3)$ to medium $(\mathrm{C} 2.2)$ bedded. The mud-silt ratio of the $\log$ is approximately $1: 10$.

\section{Depositional setting:}

The lithofacies associations documented within the lower part of the section suggest a proximal setting, possibly developing from intermediate lobe towards channel-lobe transition. Distal lithofacies and consistent coarsening-up trends in the upper part of the section point towards an outer lobe setting.

\section{References:}

Bouma, A. H. 1962. Sedimentology of some flysch deposits, a graphic approach to facies interpretation. Elsevier Co, Amsterdam, pp 1-168.

Mutti, E. \& Ricci Lucci, F. 1972. Le torbiditi dell'Apennino settentrionale: intoduzione all'analisi di facies. Mem. Soc. Geol. Italy, 11, 161-99.

Mutti, E. \& Normark, W. R. 1987. Comparing examples of modern and ancient turbidite systems; problems and concepts. In: Legget, J. K. \& Zuffa, G. G. (eds) Marine clastic sedimentology; concepts and case studies. Graham and Trotman, London, pp 1-38.

Pickering, K. T., Hiscott, R.N. \& Hein, F.J. 1989. Deep Marine Environments. Unwin Hyman, London, United Kingdom, pp1-416.

Pickering, K. T., Clark, J. D., Smith, R. D. A., Hiscott, R. N., Ricchi Lucci, F., Kenyon, N. H. 1995. Architectural element analysis of turbidite systems, and selected topical problems for sand-prone deep-water systems. In: Pickering, K. T., Hiscott, R. N., Kenyon, N. H, Ricchi Lucci, F. \& Smith, R. D. A. (eds) Atlas of deep water environments - Architectural style in turbidite systems. Chapman and Hall, London, pp 1-10. 